\title{
Prevalence and factors associated with safe sex behaviors among \\ adolescent vocational students
in Nakhon Ratchasima \\ adolescent vocational stude
in Nakhon Ratchasima Province, Thailand
}

\author{
Maneebongkot Chaumaroeng and Alessio Panza \\ College of Public Health Sciences, Chulalongkorn University, Bangkok, Thailand
}

\begin{abstract}
Purpose - The purpose of this paper is to describe the prevalence and factors associated with safe sex behavior among vocational students in Nakhon Ratchasima Province, Thailand, and to determine the modifying factors listed as socio-demographic characteristic, the level of HIV and sexually transmitted infections' knowledge, attitude toward reproductive health, and safe sex behavior among vocational students in Nakhon Ratchasima Province, Thailand.

Design/methodology/approach - A cross-sectional descriptive research was conducted from August to October 2018. The multistage stratified sampling, combined with purpose and random sampling, was used to select the participants. One vocational college with the highest number from urban, suburban and rural areas was purposely selected. The sample calculation by using Cochran's formula, a random sampling by drawing from each college with male and female, was made to obtain the sample size of 355 students. Inclusion criteria included: vocational students, both male and female, aged between 15 and 19 years, resided in the study area, and volunteered to participate. Ethical consent including waiver of the parent's consent for the participant aged under 18 years for this study was approved by the Institution Review Board for Human Research Ethics, Chulalongkorn University (Certification number JV 823/2561) A self-administered questionnaire was adapted by the principle researcher from the illustrative questionnaire for interview survey with young people (14), and The study of Prevalence of HIV, STD, Drug Use and Risk Behaviors in Adolescents and Young Adults, in Chaing Rai, Thailand (PRAYA) tool (15). All statistical analyses were performed by SPSS version 22.

Findings - The finding revealed that 332 participants were male ( 57.8 percent) and female ( 42.2 percent) with an average age of 16.8 years $( \pm 1.7)$. Approximately 60 percent of males and 50 percent of females had experience of sexual intercourse, with their first experience of sexual intercourse at the average age of 15 . Most respondents 63.1 percent used a condom and 63.6 percent used contraception in their latest sexual intercourse. About 41.9 percent consumed alcohol and 15 percent reported substance abused. Sexual intercourse among adolescents vocational students were significantly associated with high knowledge of contraception $(\mathrm{OR}=0.30,95 \% \mathrm{CI}=0.10-0.82)$. Positive attitude toward reproductive health had a significant association with sexual intercourse $(\mathrm{OR}=0.17,95 \% \mathrm{CI}=0.05-0.58)$. Sexual intercourse among vocational students were also significant associated with low risk behavior $(\mathrm{OR}=0.45,95 \% \mathrm{CI}=0.22-0.91)$ and high risk behaviors $(\mathrm{OR}=0.24,95 \% \mathrm{CI}=0.10-0.59)$. Contraceptive used in the latest sexual intercourse had a significant association with cues to action $(\mathrm{OR}=0.43,95 \% \mathrm{CI}=0.22-0.86)$.

Research limitations/implications - This study used a self-reported questionnaire to collect information from participants about safe sex behaviors, which might contain bias data and socially desirable answers. The time for collecting data did not match vocational students' schedule as they were about to have their final exams. An error in this questionnaire was the absence of condom use as one of the contraception methods. Practical implications - The study showed that both male and female vocational students in Nakhon Ratchasima have a low level of knowledge of HIV, STIs and contraception. This study revealed that females have higher knowledge of all the factors more than males. Males usually received more harassment from peers for being sexually active than females do. Condoms and contraceptive used are inconsistent in all
\end{abstract}

(c) Maneebongkot Chaumaroeng and Alessio Panza. Published in Journal of Health Research. Published by Emerald Publishing Limited. This article is published under the Creative Commons Attribution (CC BY 4.0) licence. Anyone may reproduce, distribute, translate and create derivative works of this article (for both commercial and non-commercial purposes), subject to full attribution to the original publication and authors. The full terms of this licence may be seen at http://creativecommons.org/ licences/by/4.0/legalcode

Received 28 March 2019 Accepted 22 April 2019 
JHR

34,1 research conducted and have no common ground. Communication related to sex for those who have no partner was poor compared to students who have a partner. The four factors associated with safe sex behaviors should always be considered and surveyed among vocational students, as the study showed that all results vary for a future adolescence study.

Social implications - This research aims at government authorities. The policy makers should include reproductive health and rights in the curriculum. The Ministry of Public health and The Ministry of Education should provide training for the trainer program for teachers concerning safe sex behaviors. For future research, in-depth interview and qualitative study should be used to increase the reliability of the result of the inconsistency of using a condom and contraception. The researcher should do further studies into vocational college semester schedules before collecting data and should spend more time in the college, so the students become more acquainted to the researcher and give a more truthful answer. Moreover, condom use should be added as one of the contraception methods.

Originality/value - This is the first study among vocational students in Nakhon Ratchasima Province which emphasizes specifically on safe sex behaviors and factors related to it. Regarding the population of vocational students, this study covers almost 80 percent of the population. Sensitive questions for sexual activity status and sexually history were answered by a self-administered questionnaire in order to increase sincere answers on their experiences because participants were not shy to disclose their sexual experiences.

Keywords Adolescent health, Health belief model, Safe sex behaviours, Thailand

Paper type Short report

\section{Introduction}

Adolescence, broadly defined by the WHO as between the ages of 10 and 19, is a critical life stage marking the transition from childhood to adulthood[1]. An adolescent's knowledge of safe sex behaviors is an essential aspect of learning, particularly to those living in social and cultural conditions that might put them at risk of premature unsafe sexual behaviors[2]. In Thailand, 13.3 percent of the total population are adolescents[3]. The Bureau of Epidemiology found that youth aged between 15 and 24 years were at greater risk of sexually transmitted infections (STIs) with rates likely to increase[4]. Moreover, unintended pregnancy results in adolescents facing numerous life barriers, including social stigma and the potential risk of complications from clandestine abortions[5]. An estimated 200,000-300,000 women of reproductive age seek an abortion each year while early marriage and unwanted pregnancy are the main reasons for adolescent girls to drop out of school[2]. The explosive increase in adolescent pregnancies partly stems from an increase in sexual relationships outside of marriage and irregular contraception use (a 2008 study found only a 16 percent usage rate) $[2,6]$. Thai public health authorities now recognize the urgent need to develop preventive intervention and educational programs amongst adolescents.

Vocational education provides students with an opportunity to continue with their studies after completion of high school[7]. In Bangkok, students in the vocational system have received negative judgmental attitudes from society and the press due to inadequate knowledge and multiple outbreaks of violence amongst peer groups[2]. In this context, they are a vulnerable population as they receive inadequate support in relation to health and education on safe sex behaviors.

Nakhon Ratchasima Province has the second largest number of vocational students in Thailand. This study aims to address the paucity of research assessing the prevalence and factors associated with safe sex behaviors among vocational students in Nakhon Ratchasima Province, Thailand. The outcomes of this research could provide useful data for the Nakhon Ratchasima provincial public health officials to plan an ongoing safe sex curriculum in vocational colleges and schools.

\section{Methodology}

A cross-sectional descriptive research study was conducted from August to October 2018 to identify the prevalence and factors associated with safe sex behaviors among adolescent vocational students in an urban, suburban and rural areas in Nakhon Ratchasima Province, Thailand. The multistage stratified sampling combined with purposive and random 
sampling was used to select the participants. Purposive sampling was used to select Nakhon Ratchasima Province because it had the highest number of vocational students in the northeast region (23,558 students). The government vocational college was purposively selected because of the highest number of Por vor chor year 1-year 3 students $(19,236$ students). The sample size of 355 students was calculated by using Cochran's formula and purposively selected from each location proportion of the highest number of students enrolled. Out of the 355 sample size, 190 (54 percent) students were from urban, 92 students (26 percent) from suburban and 73 (20 percent) students were from the rural area. Random sampling by drawing respondents from each college with equal numbers of male and female participants was made to reach the sample size (355 students). Inclusion criteria were volunteer single male and female vocational students aged between 15 and 19 years who resided in their study area.

Ethical consent including waiver of the parent's consent for participants aged under 18 years was approved by the Institution Review Board for Human Research Ethics, Chulalongkorn University (Certification number JV 823/2561).

\section{Instruments}

The principal researcher adapted two self-administered questionnaires, first, from the WHO illustrative questionnaire for interview-surveys with young people[8], and, second, the study of Prevalence of HIV, STD, Drug Use and Risk Behaviors in Adolescents and Young Adults, in Chaing Rai, Thailand (PRAYA) tool[9]. The research instruments consisted of four parts: part 1 being for socio-demographic characteristics, knowledge of HIV, STIs, contraception, attitude toward reproductive health, risk behaviors and communication skills. Parts $2-4$ was adapted from the Health Belief Model constructs of four subscales of HIV, STIs and intention of condom use, including self-efficacy and cues to action. Part 5 was composed of safe sex behavior to obtain information on abstinence, contraceptive and condoms used. For content validity of communication skills and cues to action, three experts were evaluated by the items objective congruence (IOC), giving a rating of -1 (clearing not measuring), or 0 (uncertain measuring) and 1 (clear measuring). A pilot study was conducted amongst 35 students from another vocational college in Nakhon Ratchasima municipality to test the reliability of knowledge, attitude, perceptions and self-efficacy, the summary of each item ranging from 1 to 4 . The Kuder-Richardson test (KR-20) for pretest knowledge of HIV/STIs, contraception and reproductive health were 0.96, 0.97 and 0.93, respectively, and after data collection were $0.89,0.88$ and 0.80 . Cronbach's alpha of attitude toward reproductive health, perceptions and self-efficacy of pretest were $0.90,0.94$, and 0.88 , respectively, and after data collection were $0.85,0.86$ and 0.82 .

All statistical analyses were performed by SPSS version 22; the population characteristics were described by frequency and percentage. Mean and standard deviation described the level of knowledge, level of attitude, level of risk behaviors (alcohol consumption, smoking and drug abuse). The following were deemed as levels to consider for conduction mean and standard deviation: perceptions (perceived susceptibility, perceived severity, perceived barrier and perceived benefits) self-efficacy and cues to action in order to determine the factors associated with safe sex behaviors by bivariate analysis and multivariate analysis. $p<0.05$ was regarded as being statistically significant.

\section{Results}

Of the 355 sample size, 3 students who did not confirm their gender and 20 who were above 19 years $(n=20)$ were excluded, resulting in a final total of 332 students recruited to this study. This total included 192 (57.8 percent) males and 140 (42.2 percent) females with an average age of 16.8 years $( \pm 1.7)$. There were 117 ( 62.8 percent) males and 70 (50.5 percent) females who had experience of sexual intercourse. Safe sex behaviors during sexual
Safe sex behaviors 
JHR

34,1

82

intercourse were commonly reported amongst participants aged 15 years, with a GPA of $\leqslant 2.50$ and an income of less than $5,000 \mathrm{THB} /$ month (Table I).

The average score of knowledge related to HIV and STIs, contraception, and reproductive health was low ( $<60$ percent correct answers). Males ( 45.3 percent) had a lower knowledge than females (40.7 percent). Participants mostly responded correctly to questions about HIV being transmitted by blood transfusion, sharing contaminated needles and sexual intercourse. The most known STIs were Gonorrhea, Chlamydia and Syphilis, with the best-known symptoms for STIs being discharges from the genital organ. However, most students (74.7 percent) went to the government hospital for treatment and 33.4 percent went to drug stores. Regarding hearing about contraception, condoms (80.1 percent) were the most well-known among students, followed by the use of emergency contraceptive pills (76.8 percent) and the oral contraceptive pill (76.2 percent). However, only 60 percent had knowledge of how to use contraception effectively. Most students (68.7 percent) had a neutral attitude level toward reproductive health.

There was no major difference between high (22.6 percent) and low (23.8 percent) risk participants for alcohol consumption, smoking and substance abuse. In sum, 21.4 percent of participants experienced sexual harassment with males (28.6 percent) having a higher percentage than females (11.4 percent).

About 64.8 percent of participants had low levels of perceived susceptibility to HIV/AIDS with low pregnancy susceptibility. In sum, 55.2 percent had high levels of perceived severity of HIV, STIs and pregnancy; 62.0 percent has high levels of self-efficacy of avoiding sex and condom use during intercourse.

In sum, 51.8 percent of participants had high-level cues to action. Males (53.6 percent) had higher levels than females (49.3 percent); 52.4 percent used the internet for sexual issues and less than 40 percent used the internet for chatting about sex and viewing pornography; 64.2 percent attended health education in college; 44.0 percent practiced safe sex behavior because friends experienced symptoms of STIs; 46.7 percent were influenced by family and 51 percent by peers to practice safe sex; and 58.1 percent agreed to avoid sex before marriage and 47.3 percent agreed that boys should practice safe sex before marriage.

Regarding safe sex behaviors, 60.9 percent of male and 50 percent of female participants were sexually active. In sum, 23.6 percent of females and 19.8 percent of

\begin{tabular}{|c|c|c|c|}
\hline Variables & Male $(n=192)(\%)$ & $\begin{array}{r}\text { Population groups } \\
\text { Female }(n=140)(\%) \\
\end{array}$ & Overall $(n=332)(\%)$ \\
\hline \multicolumn{4}{|l|}{ Location } \\
\hline Urban & $110(57.3)$ & $67(47.9)$ & 177 (53.3) \\
\hline Suburban & $45(23.4)$ & 37 (26.4) & $82(24.7)$ \\
\hline Rural & 37 (19.3) & 36 (25.7) & $73(22.0)$ \\
\hline \multicolumn{4}{|l|}{ Age (years) } \\
\hline & $31(16.4)$ & $27(19.6)$ & $58(17.7)$ \\
\hline $16-17$ & $98(51.9)$ & $64(46.4)$ & $162(49.5)$ \\
\hline 18-19 & $60(31.7)$ & $47(34.1)$ & $107(32.7)$ \\
\hline \multicolumn{4}{|l|}{ Grade point average (GPA) } \\
\hline $1.00-2.50$ & $41(21.4)$ & $11(7.9)$ & $52(15.7)$ \\
\hline $2.51-3.00$ & $58(30.2)$ & $50(35.7)$ & 108 (32.5) \\
\hline $3.01-3.50$ & $46(24.0)$ & $42(30.0)$ & 88 (26.5) \\
\hline $3.51-4.00$ & $43(22.4)$ & $35(25.0)$ & $78(23.5)$ \\
\hline \multicolumn{4}{|l|}{ Monthly income } \\
\hline$<\mathrm{U} \$ 150(<5,000 \mathrm{THB})$ & $119(62.0)$ & $75(53.6)$ & $194(58.4)$ \\
\hline$\geqslant \mathrm{U} \$ 150(\geqslant 5,000 \mathrm{THB})$ & 27 (14.6) & $45(32.1)$ & $73(22.0)$ \\
\hline
\end{tabular}

Table I.

Frequency and percentage of adolescent vocational student characteristics
$<\mathrm{U} \$ 150(<5,000 \mathrm{THB})$

$27(14.6)$
$45(32.1)$ 
males intended to use condoms during their first sexual intercourse experience. Amongst the sexually active students, 79.5 percent males and 79.7 percent of females used a condom during first sexual intercourse, but only 65 percent of males and 60 percent of females used condoms during their latest sexual intercourse. In sum, 71.0 percent of males and 81.4 percent of females used contraception during first sexual intercourse. Only 60.7 percent of males and 68.6 percent of females used contraception during their latest sexual intercourse. Oral contraceptive pills (58.8 percent) were the most popular contraceptive used among sexually active students.

\section{Relationship between factors and safe sex behaviors}

Table II shows the statistical significance of the relationship between several factors and abstinence from sexual intercourse. The relationship of neutral attitudes (41.0 percent) was

\begin{tabular}{|c|c|c|c|c|c|}
\hline Factors & $\begin{array}{c}\text { Have you ever } \\
\text { Yes } \\
n(\%)\end{array}$ & $\begin{array}{l}\text { al intercourse? } \\
\text { No } \\
n(\%)\end{array}$ & $\chi^{2}$ & $p$-value & \\
\hline Sex & & & 3.937 & $0.047^{*}$ & \\
\hline Male & $117(35.2$ & $75(22.6)$ & & & \\
\hline Female & $70(21.1)$ & $70(21.1)$ & & & \\
\hline Grade point average (GPA) & & & 5.668 & $0.017^{*}$ & \\
\hline$<2.00$ & 37 (11.3) & $15(4.6)$ & & & \\
\hline$\geqslant 2.00$ & $146(44.5)$ & $130(39.6)$ & & & \\
\hline Knowledge of contraception & & & 7.297 & $0.026^{*}$ & \\
\hline Poor & $85(28.4)$ & $68(22.7)$ & & & \\
\hline Moderate & $46(15.4)$ & 38 (12.7) & & & \\
\hline Good knowledge & $46(15.4)$ & $16(5.4)$ & & & \\
\hline Knowledge of reproductive health & & & 10.034 & $0.007^{* *}$ & \\
\hline Poor & $130(39.6)$ & 123 (37.5) & & & \\
\hline Moderate & $30(9.1)$ & $11(3.4)$ & & & \\
\hline Good knowledge & $24(7.3)$ & $10(3.0)$ & & & \\
\hline Attitude reproductive health & & & 21.963 & $0.000 * * *$ & \\
\hline Negative & $15(4.6)$ & $37(11.2)$ & & & \\
\hline Neutral & $135(41.0)$ & $94(28.6)$ & & & \\
\hline Positive & $35(10.6)$ & $13(4.0)$ & & & \\
\hline Risk behavior (alcohol, smoking, drug use) & & & 28.346 & $0.000 * *$ & \\
\hline No risk & $55(19.2)$ & $77(26.9)$ & & & \\
\hline Low risk & $50(17.5)$ & $29(10.1)$ & & & \\
\hline High risk & $59(20.6)$ & $16(5.6)$ & & & \\
\hline Sexual harassment & & & 12.607 & $0.000 * *$ & \\
\hline Yes & $130(39.4)$ & $127(38.5)$ & & & \\
\hline No & $54(16.4)$ & $19(5.8)$ & & & \\
\hline Perceived susceptibility & & & 6.612 & $0.010^{*}$ & \\
\hline Low & $105(31.5)$ & $101(30.3)$ & & & \\
\hline High & $83(24.9)$ & $44(13.2)$ & & & \\
\hline Perceived severity & & & 4.844 & $0.028^{*}$ & \\
\hline Low & $73(22.1)$ & $74(22.4)$ & & & \\
\hline High & $113(34.2)$ & $70(21.4)$ & & & \\
\hline Perceived barriers & & & 14.567 & $0.000^{* *}$ & \\
\hline High & $84(25.4 \%$ & $97(29.3)$ & & & \\
\hline Low & $101(30.5)$ & $49(14.8)$ & & & \\
\hline Cues to action & & & 6.759 & $0.009 * *$ & \\
\hline Low & $63(20.4)$ & $68(22.4)$ & & & Relationship between \\
\hline High & $109(35.9)$ & $65(21.4)$ & & & factors and abstinence \\
\hline Note: $* p<0.01 ; * * p<0.05 ; * * * p<0.001$ & & & & & (no sexual intercourse) \\
\hline
\end{tabular}

Safe sex behaviors

\begin{abstract}
absing from
\end{abstract}


JHR

34,1

84

Table III.

Relationship between factors associated with condom use during the latest sexual intercourse statically significant with sexual intercourse. High-risk behavior including drinking alcohol, smoking, drug use (Yaa baa, ice) (20.6 percent) and sexual harassment (39.4 percent) were strongly statistically significant with sexual intercourse $(p<0.001)$.

Table III shows the relationship between factors and condom use in the latest sexual intercourse, showing that the relationship between poor knowledge of contraception (30.8 percent) and high level of cues to action were statistically significant $(p<0.05)$ (Table IV).

Table V shows logistic regression analysis with safe sex behaviors, high knowledge of contraception significant association with abstinence/no sexual intercourse. The odds of not using contraception in the latest sexual intercourse were four times higher amongst vocational students who had a high level of cues to action.

\section{Discussion}

Male adolescences were more sexually active than female vocational students in Nakhon Ratchasima Province. This is comparable to other research amongst similar groups that found that culture and attitude amongst young adults in rural and urban areas determined safe sex behaviors that varied by gender[10]. This study is similar to another conducted in northern Thailand and shows that males have a poor level of knowledge of HIV, STIs and

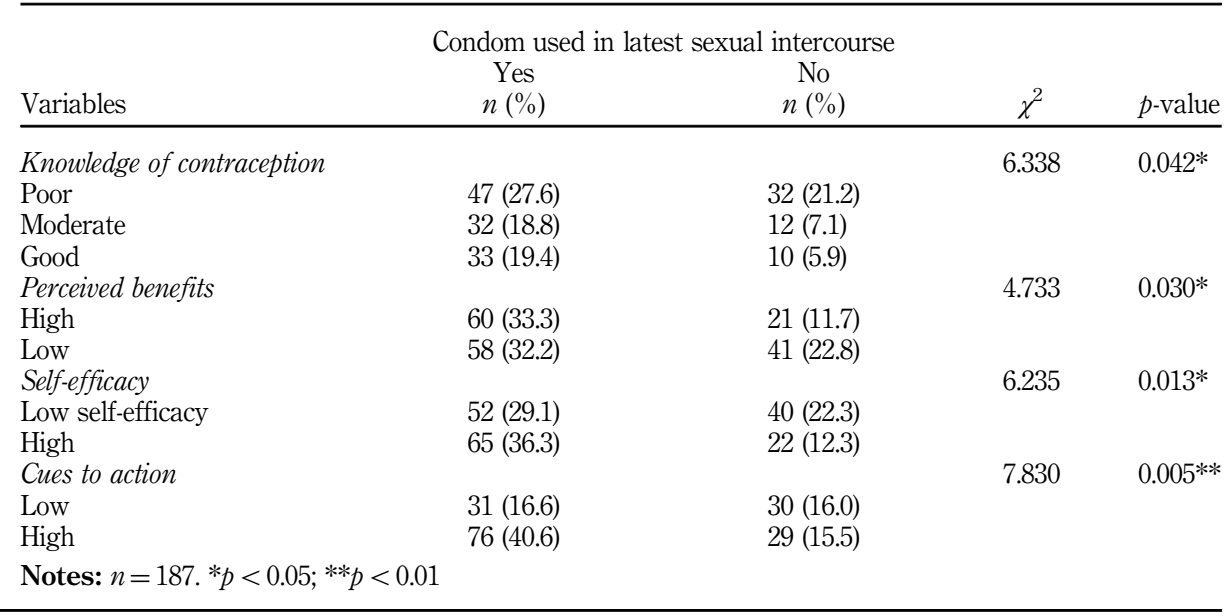

\begin{tabular}{lcccr}
\hline \multicolumn{1}{c}{$\begin{array}{c}\text { Contraceptive used in the latest sexual intercourse } \\
\text { Yes } \\
n(\%)\end{array}$} & $\begin{array}{c}\text { No } \\
(\%)\end{array}$ & $\chi^{2}$ & $p$-value \\
Variables & & & 7.060 & $0.029^{*}$ \\
\hline Knowledge of contraception & $53(30.8)$ & $28(16.3)$ & & \\
$\quad$ Poor & $23(13.4)$ & $21(12.2)$ & & \\
$\quad$ Moderate & $37(21.5)$ & $10(5.8)$ & 6.006 & $0.014^{*}$ \\
$\quad$ High & $21(40.4)$ & $10(19.2)$ & & \\
$\quad$ ues to action & $10(19.2)$ & $11(21.2)$ & & \\
$\quad$ High & & & & \\
$\quad$ Low & & &
\end{tabular}




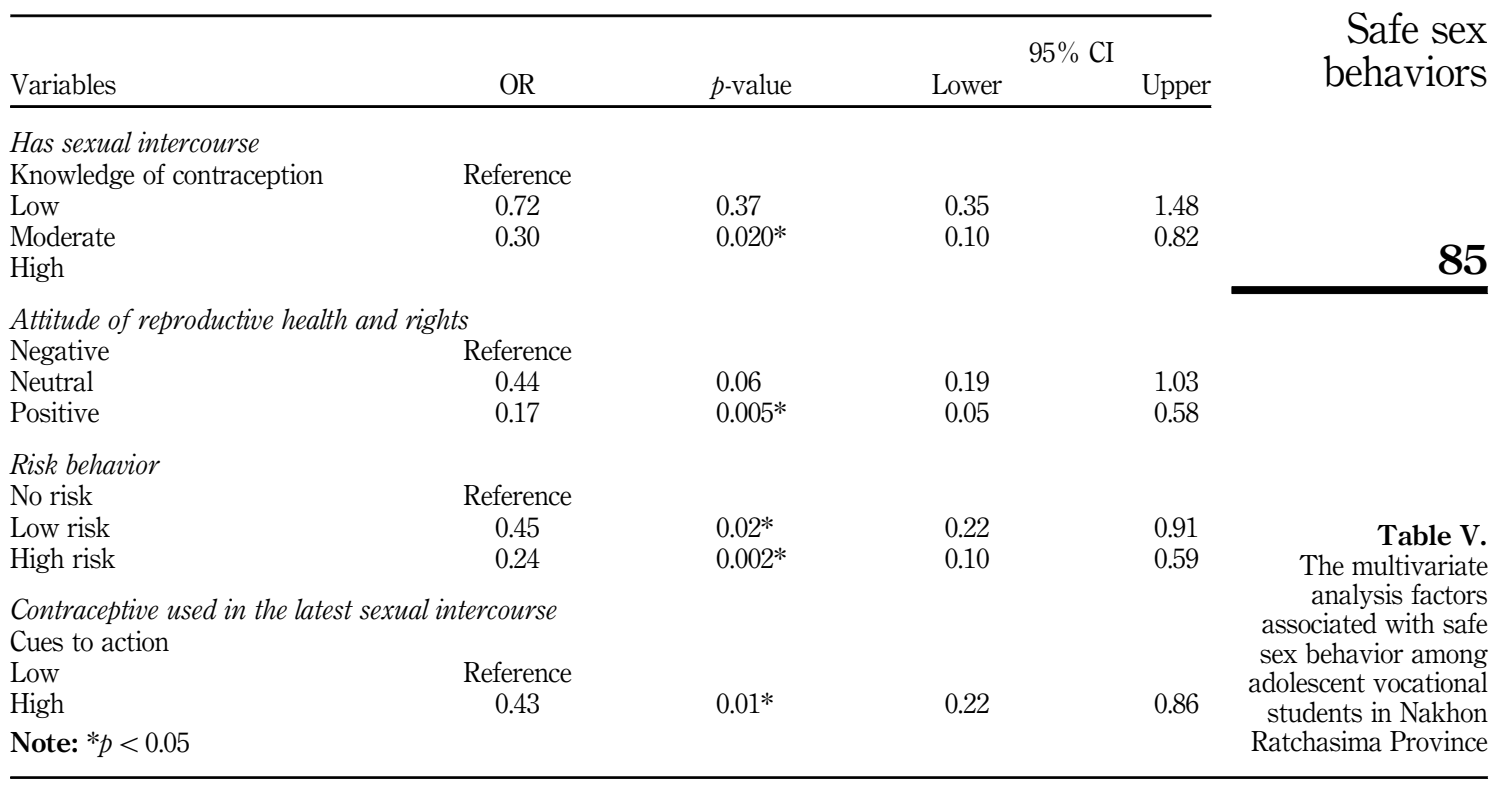

contraception compared to females[11]. Moreover, this study confirmed that students with a higher GPA were associated with abstinence; showing similarities to another study of high school students with higher grades who delayed engaging in sexual intercourse[12]. An interesting outcome of this research was the low and high-risk behaviors showing a significant negative association between alcohol consumption, smoking and substance abuse associated with sexual intercourse. However, there were no significant connections between condom use and contraceptive use. Similarly, there were significant negative correlations between drug and alcohol use and contraception[13]. Sexual harassment in this study corresponds with sexual intercourse, whereas males (28.6 percent) experienced sexual harassment more than females (11.4 percent) that can be compared to a study of adolescents in the USA where over half the students were physically and verbally harassed by their classmates[14]. A study of high school and vocational schools in Thailand found that males provoked violence during a relationship more than females[15]. Most students had neutral attitudes toward safe sex behaviors suggesting that most of them ignored warnings about practicing safe sex. Another study found that there was a negative attitude shown toward girls who engage in premarital sex, but neutral attitudes toward boys[16]. Communication related to sex was high amongst students who have partners suggesting that these students paid more attention to condoms and contraceptives to prevent pregnancy and diseases (participants have a low level of perceived susceptibility of HIV/AIDS and unwanted pregnancy). This study is further supported by a study of college students in the USA where only 50 percent of students were concerned about STIs during sexual intercourse[17, 18]. Finally, this study, similar to a study in Udon Thani Province of Northeastern Thailand, revealed that Thai traditions still have an influence on vocational students[15].

\section{Conclusion}

This study indicates that both male and female vocational students in Nakhon Ratchasima had low levels of HIV, STIs and contraception knowledge. Females had a 
higher knowledge of all the factors compared to males while males received more harassment from peers for being sexually active. This study used a self-reported questionnaire to collect information from participants and therefore, may include biased data containing socially desirable answers. Furthermore, the timing of data collection coincided with final year exams.

Recommendation

Government and policy makers should include reproductive health education and rights in the curriculum. Furthermore, the Ministry of Public health and The Ministry of Education should provide training for teachers to promote safe sexual behaviors within the curriculum. Future researchers should find ways to gain the confidence of participants in order to gain more truthful answers for more accurate reporting.

\section{References}

1. United Nations Population Fund [UNFPA]. Sexual and reproductive health of young people in Asia and the Pacific: a review of issues, policies, and programmes. Bangkok: UNFPA; 2015.

2. United Nations Population Fund [UNICEF]. A situation analysis of adolescents in Thailand 2015-2016. Bangkok: UNICEF; 2016.

3. National Statistical Office of Thailand. Population: statistics. Bangkok: NSO; 2016.

4. Ministry of Public Health, The Bureau of Epidemiology. Annual report of Bureau of AIDS, TB, and STIs. Bangkok: The Bureau of Epidemiology; 2016.

5. Baokhumkong C, Leetongdee S, Rohitrattana J, Jaichuang S. Factors associated with premature sexual activity among early adolescents in Ubon Ratchathani Province, Thailand. J Health Res. 2017; 31(6): 465-71.

6. United Nations Children's Fund [UNICEF]. Situation analysis of adolescent pregnancy in Thailand Synthesis Report 2015. Bangkok: UNICEF; 2015.

7. Pimpa N, Suwannapirom S. Thai students' choices of vocational education: marketing factors and reference groups. Educ Res Policy Prac. 2008; 7(2): 99-107.

8. Cleland J. Illustrative questionnaire for interviewsurveys with young people. [cited 2018 Jul 1]. Available from: www.who.int/reproductivehealth/topics/adolescence/questionnaire. pdf

9. Griensven Fv, Manopaiboona C, Kilmarxa PH, Chaikummaoa S, Jeeyapanta S, Limpakarnjanarata K, et al. High rates of pregnancy among vocational school students: results of audio computer-assisted self-interview survey in Chiang Rai, Thailand. J Adolesc. 2003 Oct; 26(5): 517-30.

10. Rasamimari A, Dancy B, Talashek M, Park CG. Predictors of sexual behaviors among Thai Young adults. J Assoc Nurses Aids Care. 2007; 18(6): 13-21.

11. Yamaguchi Y, Sriareporn P, Khiaokham P, Numtapong P, Tanaka Y, Matsuo H. Knowledge, attitude, and practice concerning the prevention of STIs among high school students in Northern, Thailand. Universal J Public Health 2016; 4(1): 8-15.

12. Roojanavech S, Badr LK, Doyle J. What variables including spirituality determine early sexual initiation among Thai adolescents? Pediatr Dimens. 2016; 1(1): 34-8.

13. Khumsaen N, Gary FA. Determinants of actual condom use among adolescents in Thailand. J Assoc Nurses Aids Care. 2009; 20(3): 218-29.

14. Pellegrini AD. Bullying, victimization, and sexual harassment during the transition to middle school. Educ Psychol. 2002; 37(3): 151-63.

15. Pradubmook-Sherer P. Prevalence and correlates of adolescent dating violence in Bangkok, Thailand. J Sociol Soc Welfare. 2009; 36(1): 9-37. 
16. Sridawruang C, Crozier K, Pfeil M. Attitudes of adolescents and parents towards premarital sex in rural Thailand: a qualitative exploration. Sex Reprod Healthc. 2010 Nov; 1(4): 181-7.

17. Downing-Matibag TM, Geisinger B. Hooking up and sexual risk taking among college students: a health belief model perspective. Qual Health Res. 2009 Sep; 19(9): 1196-209

18. Wongtongkam N, Ward PR, Day A, Winefield AH. The influence of protective and risk factors in individual, peer and school domains on Thai adolescents' alcohol and illicit drug use: a survey. Addict Behav. 2014; 39(10): 1447-51.

\section{Corresponding author}

Maneebongkot Chaumaroeng can be contacted at: bchaumaroeng@yahoo.com

For instructions on how to order reprints of this article, please visit our website: 